\title{
Reductions in root aphid populations by non-toxic endophyte strains in tall fescue
}

\author{
J.G. JENSEN and A.J. POPAY \\ AgResearch, Ruakura Research Centre, Private Bag 3123, Hamilton \\ joanne.jensen@agresearch.co.nz
}

\begin{abstract}
In two separate pot trials, tall fescue plants infected with the endophyte strain AR542, which is non-toxic to livestock, were shown to have lower numbers of root aphid per plant compared with uninfected plants, but more aphids than plants infected with other non-toxic endophytes (AR502, AR510 and AR514). These differences were not always significant when aphid numbers per gram of root were analysed. A Petri dish trial investigated the mechanism of resistance. Aphid survival was lower on endophyte-free fescue than on AR514- and AR542-infected fescue. Compared with endophyte-free, fewer aphids on roots of AR514- and AR542-infected tall fescue showed signs of feeding, as measured by production of wax and honey dew, and more were mobile on and around roots.
\end{abstract}

Keywords: Aploneura lentisci, Festuca arundinacea, Neotyphodium

\section{Introduction}

In New Zealand pasture production and persistence is greatly improved by the presence of an endophyte (Neotyphodium sp.) in grasses, due mainly to the protection endophyte provides from insect attack. Infection of tall fescue (Festuca arundinacea Schreb) with endophytes including AR542 (MaxPTM) which are non-toxic to grazing livestock increases yield of tall fescue compared with endophyte-free tall fescue in New Zealand (Cooper et al. 2002; Easton et al. 2004) and Australia (Wheatley et al. 2003). AR542 is known to provide protection against a range of insect pests (Pennell \& Ball 1999; Popay 2004), but there is some indication that it is less effective against aphids than the toxic wild-type endophyte ( $N$. coenophialum) ((Bultman et al. 2006; Hunt \& Newman 2005).

Root aphid, Aploneura lentisci, is common in pasture throughout New Zealand and has been shown in pot trials to reduce growth of ryegrass when plants are under stress (Popay \& Jensen 2005). It is therefore likely to be an important pest in drought-prone areas where tall fescue would be used. Popay \& Jensen (2005) found more root aphid under endophyte-free (Nil) than AR542 and AR501 field plots in a trial at Aorangi, New Zealand, but differences were not statistically significant. This paper describes experiments to further assess the efficacy of several non-toxic novel endophyte strains on root aphid and to investigate whether the effect is due to deterrence or toxicity.

\section{Methods}

\section{Trial A}

In spring 2000, 4-year-old tall fescue plants cv. Kentucky (KY31) without endophyte or infected with one of three novel endophytes (AR514, AR510, AR542) and 1-year old Advance tall fescue without endophyte or infected with one of two endophytes (AR502, AR542) were re-potted into $15 \mathrm{~cm}$ diameter plastic pots containing potting mix. Plants were kept for a further year in a shade-house under natural light and temperature conditions and top-watered as required. Natural populations of root aphid were allowed to develop. Endophyte infection was confirmed by tissue-print immunoblot (Hahn et al. 2003) when plants were harvested. The number of replicates for each treatment is given in Table 1 .

Plants were destructively harvested in spring 2001 and root aphid sampled by wet sieving. Roots were recovered and washed thoroughly before being oven dried and weighed. Samples containing root aphids were all diluted to $100 \mathrm{ml}$ and a subsample of $10 \mathrm{ml}$ taken. The subsample was transferred to a $9 \mathrm{~cm}$ Petri dish with a grid (approx. $1 \mathrm{~cm}^{2}$ ) drawn on the bottom. Numbers of root aphid were counted in the entire subsample under a stereo microscope at $16 \times$ magnification.

Number of root aphid per plant and number per gram of root were analysed by ANOVA, using Genstat, 5th Edition, Release 4.22 as a $2 \times 2$ factorial plus 3 (KY31 vs Advance, Nil vs AR542 + three other cultivar $\times$ endophyte combinations). All data required $\log _{\mathrm{e}}(\mathrm{n}+1)$ transformation. Because of the large variation

Table $1 \log _{e}(n+1)$ (and untransformed) mean number of root aphids per plant and per gram of root in a pot trial with two cultivars of tall fescue, Kentucky 31 and Advance, infected with novel endophytes (Trial A).

\begin{tabular}{|c|c|c|c|c|c|c|}
\hline \multirow[t]{2}{*}{ Endophyte } & \multicolumn{3}{|c|}{------------Kentucky 31---------- } & \multicolumn{3}{|c|}{-----------------Advance----------- } \\
\hline & No. reps & No./plant & No./g & No. reps & No./plant & No./g \\
\hline Nil & 15 & $6.34(740)$ & 4.36 (109) & 15 & $6.25(847)$ & 4.04 (74) \\
\hline AR542 & 14 & $3.97(68)$ & $2.79(7)$ & 14 & $4.53(160)$ & $2.85(9)$ \\
\hline AR502 & - & - & - & 12 & $3.14(23)$ & $2.42(1)$ \\
\hline AR510 & 15 & $3.16(19)$ & $2.42(1)$ & - & - & - \\
\hline AR514 & 12 & $3.07(16)$ & $2.40(1)$ & - & - & - \\
\hline $\mathrm{SED}^{1}$ & & 0.347 & 0.208 & & 0.347 & 0.208 \\
\hline
\end{tabular}

${ }^{1}$ SEDs are for combined analysis of KY31 and Advance plants, so can be used for both within and between cultivar comparisons. 
Table $2 \log _{e}(n+1)$ (and untransformed) mean number of root aphids per sample and per gram of root in a pot trial with Kentucky 31 tall fescue uninfected or infected with Neotyphodium endophytes (Trial B).

\begin{tabular}{lll}
\hline Endophyte & No./sample & No./g \\
\hline Nil & $6.15(689)$ & $6.26(808)$ \\
WT & $3.23(20)$ & $2.23(11)$ \\
AR514 & $4.01(64)$ & $3.43(39)$ \\
AR542 & $4.59(138)$ & $3.96(58)$ \\
SED & $0.279^{\star \star *}$ & $0.334^{* \star *}$ \\
\hline *** Differences significant $(\mathrm{P}<0.001)$ \\
\hline
\end{tabular}

in the number of root aphids per plant, a rank analysis was also performed to confirm the results.

\section{Trial B}

In autumn 2003, 8-week-old KY31 tall fescue without endophyte or infected with AR542, AR514 or the wild-type (WT) were planted individually into $15 \mathrm{~cm}$ diameter plastic pots containing Ruakura peaty loam. The endophyte infection status of plants had been checked by staining and microscopic examination of leaf sheath. Plants were kept in a shade-house for a further 3 months and were then transferred to a glasshouse under ambient light and temperature conditions in June (early winter) where 10 replicates of each treatment were arranged in a randomised block design. Plants were weeded, trimmed and fertilised regularly, and natural populations of root aphids were allowed to develop.

Plants were destructively harvested over three separate dates - replicates 1-3 on 28 July, reps 4-6 on 1 September and reps 710 on 22 September. At harvest, plants were removed from each pot and the intact plant, including shoots, roots and root-bound soil was divided in half vertically. One portion was used for microbiological and nematode assessments (data not presented here). Root aphids were extracted from the other half by wet sieving and counted as described above.

Endophyte status was checked by tissue-print immunoblot prior to each harvest. One plant from the AR542 treatment was found not to contain endophyte and was therefore omitted from the analyses.

\section{Trial C}

In January (summer) 2007, $90 \mathrm{~mm}$ diameter Petri dishes were firmly packed with $60 \mathrm{ml}$ of perlite mixed with $25 \mathrm{ml}$ tap water and approximately $2 \mathrm{~g}$ Osmocote ${ }^{\circledR}$ slow release fertiliser. Two tillers with associated roots were split off individual 4-month old tall fescue cv. Jesup plants grown in potting mix and kept in a glasshouse. Plants contained either AR514 or AR542 endophyte or were endophyte-free (Nil). Tillers were placed in the Petri dishes so that the herbage emerged through an approximately 10 $\mathrm{mm}$ diameter hole cut into the edge of the base and top of each dish. The roots were splayed over the surface of the perlite before the lid was put in place. Plastic barriers were placed on either side of replicate groups of dishes placed together in random order and fastened with rubber bands. Dishes were placed on their edges in a polystyrene tray lined with felt and with strips of wood on either side of the emerging tillers to provide shade to the roots. Dishes were bottom watered and kept outside under ambient temperature and light conditions but sheltered from rain.

After 2 weeks, five replicate groups with the best root growth
Figure 1 Number of live root aphids per plant on tall fescue cv. Jesup containing AR514, AR542 or Nil endophyte at two sample dates in a Petri dish trial (Trial C). Error bars are SEM.

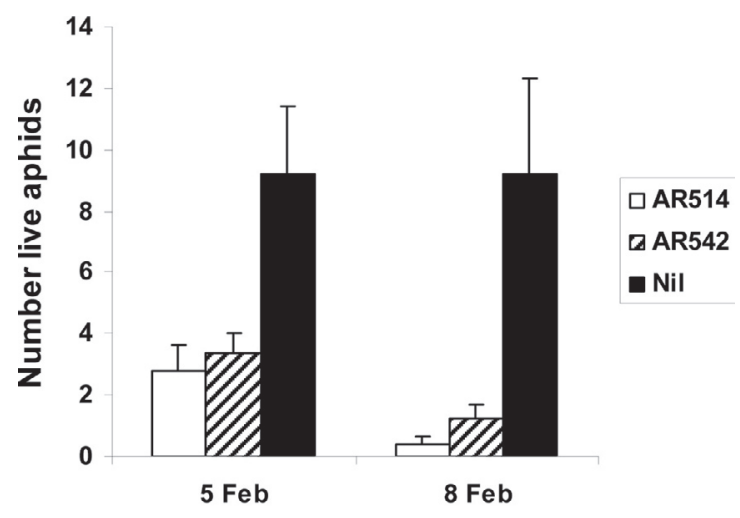

Date

were selected from each endophyte treatment. Ten root aphids of various ages were transferred from roots of ryegrass plants onto roots in each of the dishes. Dishes were re-checked after 2-3 hours and any dead or damaged aphids replaced before dishes were returned to the trays and kept outside as above. Replicates 1 and 2 were set up on 1 February 2007 and the remaining three replicates the following day. All dishes were checked on 5 and 8 February. Aphid survival, position and behaviour were noted. Presence of honeydew and wax was noted for each aphid observed. Any dead aphids were removed.

Data were analysed by ANOVA using Genstat.

\section{Results}

\section{Trial A}

There was a highly significant $(\mathrm{P}<0.001)$ effect of endophyte on root aphid numbers per sample and on root aphid per gram root (Table 1). Endophyte free plants had significantly more root aphids than endophyte infected plants. Plants containing AR542 had more root aphids than plants with the other endophytes $(\mathrm{P}<0.05)$, but this difference was not significant when numbers were calculated as root aphid per gram of root. There was no significant effect of cultivar.

Because these data were not normally distributed following $\log$ transformation, it was also analysed by rank analysis and the same result was obtained (ie. highly significant effect of endophyte) (data not shown).

\section{Trial B}

As with Trial A, endophyte had a strong effect on root aphid numbers with significantly more aphids on the Nil endophyte plants $(\mathrm{P}<0.001)$ both when calculated per sample and per gram of root. Of the endophyte treatments, WT plants had significantly fewer root aphids per sample $(\mathrm{P}<0.05)$ and per gram of root $(\mathrm{P}<0.01)$ than the two novel endophyte treatments. Although AR514 plants had fewer aphids than AR542 this difference was not statistically significant.

\section{Trial C}

After 3-4 days (5 February sample date), there were significantly more live aphids in Petri dishes containing Nil endophyte tall 
Figure 2 Percentage of live aphids producing wax or honey dew, or noted as being mobile in Petri dishes containing tall fescue cv. Jesup with AR514, AR542 or Nil endophyte, on the first sample date (5 Feb). Error bars are SEM.

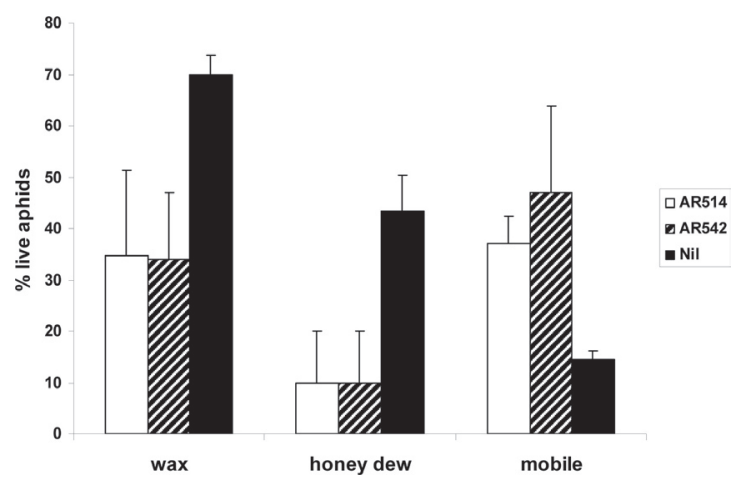

fescue than in those containing AR514 or AR542 $(\mathrm{P}<0.05)$, and this difference was even greater after 6-7 days ( 8 February sample date $)(\mathrm{P}<0.01$; Fig. 1$)$. The number of live aphids did not differ significantly between endophyte treatments but at the first sampling significantly more dead aphids were found on AR514 than on AR542 and Nil (mean number per dish $=2.8,1.0$ and 0.6 respectively \pm SED 0.63$)(\mathrm{P}<0.05)$. This difference was no longer evident at the second sample date.

Behaviour of aphids differed depending on endophyte treatment (Fig 2). A greater percentage of live aphids had produced wax on the Nil endophyte treatment than on the endophyteinfected treatments (significant only on the second sample date $(\mathrm{P}=0.01)$ ). Live aphids on Nil endophyte treatments were also more likely to be secreting droplets of honey dew, indicative of feeding, than aphids on both endophyte treatments, and this difference was statistically significant on both sample dates $(\mathrm{P}<0.05)$. The percentage of live aphids noted as being mobile, rather than feeding or remaining stationary, was greater on endophyte-infected treatments, although the difference was not statistically significant.

\section{Discussion}

Root aphid was clearly and consistently affected by the presence of $N$. coenophialum endophyte in tall fescue. The degree of activity against the aphids varied between the different endophyte strains. Although differences were not always statistically significant, tall fescue plants containing AR542 tended to have more root aphids than plants containing other novel endophytes.

It is not possible to determine from the Petri dish trial whether the effect of the endophytes on root aphid is a toxic or a deterrent one. For both endophyte-infected treatments, fewer aphids were seen to be feeding, as evidenced by the lower production of wax and honey dew, and aphids were more likely to be seen actively wandering on perlite and away from the new, growing roots. This may indicate that both endophytes have a degree of feeding deterrence. $R$. padi also tend to avoid tall fescue leaf blades infected with the endophytes AR502 and AR542 suggesting a deterrent effect (Bultman et al. 2006).

Loline alkaloids have been directly linked to adverse effects of Epichloë festucae on two aphid species, Rhopalosiphum padi and Schizaphis graminum, and can be translocated in phloem sap to roots in quantities that could be biologically significant
(Wilkinson et al. 2000). All the endophytes tested here also produce peramine in shoots but only small quantities of this alkaloid are found in roots (Ball et al. 1997). Furthermore, meadow fescue (Festuca pratensis) which produces loline alkaloids but not peramine or ergovaline is also resistant to $A$. lentisci (Schmidt 1993). Thus it seems likely that the loline alkaloids have affected root aphid in this trial.

Differences in efficacy between AR542 and other endophytes were apparent in our trials. Others have also reported that AR542 (and also AR502) in tall fescue may provide less protection against $R$. padi than the Wild-type endophyte (Hunt \& Newman 2005; Bultman et al. 2006) although this may be cultivar dependent (Bultman et al. 2006). Such differences may be due to the different types of lolines found in each strain. AR542 was the only strain used in our experiments that produces only $\mathrm{N}$ acetyl norloline and not the other major loline derivatives, $\mathrm{N}$ formyl loline and $\mathrm{N}$-acetyl loline. Other factors such as quantity of lolines in roots are also likely to be factors affecting root aphid response.

\section{ACKNOWLEDGEMENTS}

We would like to thank Catherine Cameron for data analyses.

\section{REFERENCES}

Ball, O.J.P.; Barker, G.M.; Prestidge, R.A.; Lauren, D.R. 1997. Distribution and accumulation of the alkaloid peramine in Neotyphodium lolii-infected perennial ryegrass. Journal of Chemical Ecology 23: 1419-1434.

Bultman, T.L.; Pulas, C.; Grant, L.; Bell, G.; Sullivan, T.J. 2006. Effects of fungal endophyte isolate on performance and preference of bird cherry oat aphid. Environmental Entomology 35: 1690-1695.

Cooper, B.M.; Easton, H.S.; Hume, D.E.; Popay, A.J.; Baird, D.B. 2002. Improved performance in Northland of tall fescue with a novel endophyte. pp. 379-381. In: Proceedings on the Australasian Plant Breeding Conference 12.

Easton, H.S.; Pennell, C.G.L.; Hume, D.E. 2004. Tall fescue cultivars and endophyte strains. Poster 512. In: Proceedings of the 5th International Symposium on Neotyphodium/Grass Interactions, Fayetteville, Arkansas, USA.

Hahn, H.; Huth, W.; Schoberlein, W.; Diepenbrock, W. 2003. Detection of endophytic fungi in Festuca spp. by means of tissue print immunoassay. Plant Breeding 122: 217-222.

Hunt, M.G.; Newman, J.A. 2005. Reduced herbivore resistance from a novel grass-endophyte association. Journal of Applied Ecology 42: 762-769.

Pennell, C.G.; Ball, O.J.P. 1999. The effects of Neotyphodium endophytes in tall fescue on pasture mealy bug (Balanococcus poae). pp 259-263. In: Proceedings of the 52nd New Zealand Plant Protection Conference.

Popay, A.J. 2004. Response of black beetle (Heteronychus arator), porina (Wiseana cervinata) and grass grub (Costelytra zealandica) to different endophytes in tall fescue. pp. 157163. In: Proceedings of the 8th Australasian Conference on Grassland Invertebrate Ecology.

Popay, A.J.; Jensen, J.G. 2005. Soil biota associated with endophyte-infected tall fescue in the field. New Zealand Plant Protection 58: 117-121.

Schmidt, D. 1993. Effects of Acremonium uncinatum and a Phialophora-like endophyte on vigour, insect and disease resistance of meadow fescue. pp. 185-188. In: Proceedings of the 2nd International Symposium on Acremonium/Grass 
Interactions. Eds. Hume, D.E.; Latch, G.C.M.; Easton, H.S. Palmerston Nth, New Zealand.

Wheatley, W.M.; Hume, D.E.; Kemp, H.W.; Monk, M.S.; Lowe, K.F.; Popay, A.J.; Baird, D.B.; Tapper, B.A. 2003. Effects of fungal endophyte on the persistance and productivity of tall fescue at 3 sites in eastern Australia. In: Proceedings of the 11th Australian Agronomy Conference, Geelong, Australia.
Australian Agronomy Society, CD-ROM.

Wilkinson, H.H.; Siegel, M.R.; Blankenship, J.D.; Mallory, A.C.; Bush, L.P.; Schardl, C.L. 2000. Contribution of fungal loline alkaloids to protection from aphids in a grass-endophyte mutualism. Molecular Plant-Microbe Interactions 13: 1027-1033. 